\title{
The Impact of Obesity on Various Semen Parameters and Sex Hormones in Iranian Men with Infertility: A Cross-Sectional Study
}

This article was published in the following Dove Press journal: Research and Reports in Urology

\author{
Leila Maghsoumi- \\ Norouzabad (D)' \\ Ahmad Zare Javid ${ }^{2}$ \\ Saleh Aiiashi' \\ Seyed Ahmad Hosseini ${ }^{3}$ \\ Mohammadreza Dadfar ${ }^{4}$ \\ Hadi Bazyar' \\ Maryam Dastoorpur ${ }^{5}$
}

'Student Research Committee, Ahvaz Jundishapur University of Medical Sciences, Ahvaz, Iran; ${ }^{2}$ Department of Nutrition, School of Allied Medical Sciences, Ahvaz Jundishapur University of Medical Sciences, Ahvaz, Iran; ${ }^{3}$ Nutrition and Metabolic Diseases Research Center, Ahvaz Jundishapur University of Medical Sciences, Ahvaz, Iran; ${ }^{4}$ Department of Urology, Imam Khomeini Hospital, School of Medicine, Ahvaz Jundishapur University of Medical Sciences, Ahvaz, Iran; ${ }^{5}$ Department of Biostatistics and Epidemiology, Air Pollution and Respiratory Diseases Research Center, Ahvaz Jundishapur University of Medical Sciences, Ahvaz, Iran
Correspondence: Saleh Aiiashi Department of Biochemistry, Ahvaz Jundishapur University of Medical Sciences, Golestan Street, Ahvaz, Iran Email s.aiiashi65@gmail.com
Objective: The aim of this study was to examine the correlations between body mass index (BMI) and waist circumference (WC) and semen parameters (semen volume, sperm count, motility, and morphology) and sex hormones in Iranian men with infertility.

Materials and Methods: In this cross-sectional study, a total of 119 male patients who had lived as a partner in an infertile couple for at least 1 year, after regular unprotected sexual intercourse in their married life were investigated. BMI and WC were assessed, and a morning blood sample was taken assessing serum levels of testosterone $(\mathrm{T})$, sex hormonebinding globulin (SHBG), prolactin (PRL), luteinizing hormone (LH), follicle-stimulating hormone (FSH), estradiol (E2) and leptin. Semen-analysis parameters were also measured. Results: Based on BMI and WC, the sperm count, total motility and progressive sperm were significantly lower in overweight and obese infertile males compared to that in normal weight infertile males and those with $\mathrm{WC}<102 \mathrm{~cm}$. In addition, the fraction of sperm with abnormal morphology was significantly higher in infertile men with $\mathrm{WC}>102 \mathrm{~cm}$ compared to that in those with $\mathrm{WC}<102 \mathrm{~cm}$. Moreover serum levels of $\mathrm{LH}, \mathrm{FSH}$, and leptin were significantly higher in overweight and obese infertile males compared to that in normal weight infertile males and those with $\mathrm{WC}<102 \mathrm{~cm}$. Moreover serum level of E2 was significantly higher in obese infertile males compared to the normal weight infertile males and in those with WC $>102 \mathrm{~cm}$ compared to the $\mathrm{WC}<102 \mathrm{~cm}$. Furthermore, serum level of $\mathrm{T}$ was significantly lower in obese infertile males compared to the overweight infertile males and in those with $\mathrm{WC}>102 \mathrm{~cm}$ compared to the $\mathrm{WC}<102 \mathrm{~cm}$. The mean of T/E2 ratio also was significantly lower in obese infertile males vs overweight and normal weight infertile males and in those with $\mathrm{WC}>102 \mathrm{~cm}$ compared to the $\mathrm{WC}<102 \mathrm{~cm}$.

Conclusion: We concluded that overweight and obesity in infertile men compared to those with normal weight may worsen the infertility situation.

Keywords: male infertility, obesity, semen parameters, sex hormones

\section{Introduction}

Obesity, as a major health problem, has reached epidemic extents worldwide. According to the WHO reports, nearly 650 million people were obese and more than 1.9 billion were overweight in 2016 worldwide. ${ }^{1}$ In addition to other medical conditions such as cardiovascular diseases, diabetes, osteoarthritis, and liver diseases, obesity has been shown to be associated with adult male infertility. ${ }^{2,3}$ In this regard, various studies have found that obesity is also associated with low sperm quality. $^{4-8}$ A recent systematic review with meta-analysis confirmed the 
relationship between BMI and sperm quality and suggested that obesity may be a harmful factor for male fertility. ${ }^{9}$ Also, the precise underlying mechanism by which excessive body fat reduced fertility capacity in men is still unknown. It was reported that obesity can affect the GnRH-FSH/LH pulse; impair the functions of Sertoli and Leydig cells; and thereby affect the release of sex hormones, sperm production, and maturation. ${ }^{10,11}$ Serum testosterone, gonadotropin, and sex hormonebinding globulin (SHBG) are also reported to decrease along with increasing body mass index (BMI), whereas estradiol increased with increasing BMI. ${ }^{12}$ So, these endocrine dysregulations in obese males may be associated with an increased risk of alterations in semen quality. ${ }^{13}$ On the other hand, there are numerous studies that reported contrary results in this regard. ${ }^{3,14-17}$ In a metaanalysis by MacDonald et al (2009), considering very strict inclusion and exclusion criteria, similarly there was no evidence obtained regarding the association between BMI and sperm concentration or total sperm count. ${ }^{12}$ The same results were also reported in Sermondade et al metaanalysis. ${ }^{5}$ Therefore, the available evidence on the role of obesity and BMI in male infertility is controversial. So, there is a need for improving our understanding on the underlying mechanisms, and finding appropriate interventions. In this study, we explored the correlations between BMI and WC and various semen parameters (semen volume, and sperm count, motility, and morphology) and sex hormones in Iranian men with infertility.

\section{Materials and Methods}

This cross-sectional study was conducted on 119 infertile men who met the inclusion criteria. The sample size was determined with $95 \%$ confidence interval and $80 \%$ power based on the correlation coefficient $(r=0.26)$ between the variables of $\mathrm{WC}$ and total sperm count in Fejes et al's study $^{18}$ according to the following formula: $\mathrm{N}=[(\mathrm{Z} \alpha$ $+Z \beta) / C] 2+3$. The standard normal deviate for $\alpha=Z_{\alpha}=$ 1.9600. The standard normal deviate for $\beta=Z_{\beta}=0.8416$ and $\mathrm{C}=0.5 * \ln [(1+\mathrm{r}) /(1-\mathrm{r})]=0.1820$.

Therefore, this study was performed on 119 patients who were recruited from fertility clinics between September 2018 and May 2019. The inclusion criterion was a history of infertility for at least 1 year despite regular unprotected intercourse. The exclusion criteria comprised of having definitive pathological conditions capable of affecting sperm quality such as diabetes, chronic kidney disease, and atherosclerosis; hypogonadism requiring medical treatment; genital infection; seminal tract obstruction; scrotal varicocele; and testicular cancer. Alcoholics, drug abusers, and those who received drugs affecting semen parameters or sexual hormone levels were also excluded from this study. All the subjects were provided with written informed consent and signed a standardized consent form. The Medical Ethics Committee of Ahvaz Jundishapur University of Medical Sciences approved this research (approval no.: IR.AJUMS. REC.1398.038), and it is in accordance with the Declaration of Helsinki.

A questionnaire was designed for the study, to collect demographic data and data on types and duration of infertility as well as the presence of medical conditions that affect seminal fluid parameters. Seminal fluid analysis was also performed in terms of the WHO 2010 criteria. $^{19}$ Afterwards, semen samples were taken from the participants at the fertility clinics. Parameters measured comprised of semen volume, sperm count, progressive motility, total sperm motility, and normal sperm morphology.

\section{Semen Sample Examinations}

Semen sample was collected after a minimum/maximum of 2-7 days of sexual abstinence and then transferred almost immediately to the laboratory for analysis. Semen sample examinations were conducted by trained clinical technicians. Accordingly, these semen samples were collected in a private room near the laboratory by masturbating into a sterile plastic container. The samples were then liquefied in an incubator $\left(37^{\circ} \mathrm{C}\right)$ for 30 minutes and analyzed for semen volume, sperm count, sperm motility, and normal sperm morphology during 60 minutes. Notably, semen volume was measured by weighing. To assess sperm concentration and motility, $10 \mu \mathrm{L}$ of each semen sample was placed in a Makler chamber, covered by a cover glass, and then examined at $\times 200$ magnifications. Subsequently, ten of the 100 squares in the microscope field were randomly scanned and the sperm number was recorded using a cytometer. Total motility was also defined as the sum of progressive motility and non-progressive motility. Afterwards, we calculated total sperm number as semen volume multiplied by sperm concentration, and then calculated total motile sperm count as total sperm number multiplied by total motility. Sperm morphology was assessed in terms of the WHO criteria. Following the liquefaction process, $10 \mu \mathrm{L}$ of semen was spread onto a glass slide and allowed to be air-dried at room 
temperature. The smears were then stained with Giemsa stain and sperm morphology was assessed according to the WHO criteria. Two different examiners counted 200 cells per smear using bright field illumination at a final magnification of 1000x and oil immersion. According to the WHO criteria, a morphologically normal spermatozoon has an oval head and an acrosome covering $40 \%-70 \%$ of the head area. Moreover, a normal spermatozoon has no neck, midpiece, and tail abnormalities as well as no cytoplasmic droplets larger than $50 \%$ of the sperm head.

In addition, a morning blood sample was obtained of $5 \mathrm{~mL}$ volume, which was then sent to an authorized laboratory to assess serum hormonal profile including serum testosterone $(\mathrm{T})$, follicle stimulating hormone (FSH), luteinizing hormone (LH), prolactin (PRL), sex hormone-binding globulin (SHBG), estradiol, and leptin. Testosterone, E2, and SHBG were assessed using ELISA and Diametra kits (Diametra,China). Furthermore, Luteinizing hormone (LH), follicle-stimulating hormone (FSH), and prolactin were assessed using ELISA and Pishtaz Teb kits (Pishtaz Teb, Iran). Also, Leptin was assessed by both ELISA and Diacalon kits (France)

Height was measured using a standard metal ruler when participants were standing without shoes. Weight was measured while light clothes were worn. Body mass index (BMI) was calculated using the formula [BMI = weight/(height in meters) $)^{2}$. The patients were then divided by BMI into normal weight (BMI 18-24.9 $\mathrm{kg} / \mathrm{m}^{2}, \mathrm{n}=30$ ), overweight (BMI $25-29.9 \mathrm{~kg} / \mathrm{m}^{2}, \mathrm{n}=56$ ) or obese (BMI $\left.\geq 30 \mathrm{~kg} / \mathrm{m}^{2}, \mathrm{n}=33\right){ }^{20} \mathrm{WC}$ was also measured with a standardized cloth tape measure. Then the patients were divided by $\mathrm{WC}$ into two groups $(\mathrm{WC}<102 \mathrm{~cm}, \mathrm{n}=$ 74 and $\mathrm{WC} \geq 102 \mathrm{~cm}, \mathrm{n}=45$ ).

\section{Statistical Analysis}

Data were analyzed using SPSS ver. 22 (IBM Corp., Armonk, NY, USA). Data were presented as median (range), mean standard deviation (SD) or number (percentage). Type of data distribution was determined using Kolmogorov-Smirnov test, and in the case of variables with non-normal data distribution, a nonparametric test was used to confirm the statistical significance. Chi-square test was also used to compare categorical variables and oneway analysis of variance (ANOVA) test or Kruskal-Wallis test, when appropriate, were used to compare continuous variables. Moreover, Post hoc pair-wise comparisons and Mann-Whitney test were performed in case of variables with normal data distribution and variable with non-normal data distribution, respectively. All the statistical tests were done on a two-tailed basis, and a $P$-value equal to or less than 0.05 was considered as statistically significant.

\section{Results}

A total of 119 infertile men were studied: 30 (25\%) patients had normal weight, $56(47 \%)$ patients were overweight and $33(28 \%)$ were obese. Table 1 demonstrates the demographic and clinical characteristics in the studied patients according to their BMI. No significant difference was observed in patients' age, physical activity, duration of abstinence, infertility duration, smoking, use of mobiles and economic situation among normal weight infertile males, overweight and obese groups $(\mathrm{P}>0.05)$.

Sperm counts $(P<0.001)$, total motility $(P<0.001)$ and progressive sperm $(P<0.001)$ were significantly lower in the obese groups compared to the normal weight infertile males (Table 2).

Serum levels of LH $(P<0.001)$, FSH $(P<0.001)$, and leptin $(P<0.001)$ were significantly higher in overweight and obese infertile males compared to the normal weight infertile males. In addition, serum level of $\mathrm{T}(P=0.043)$ was significantly lower in the obese group compare to the overweight. Moreover serum level of E2 $(P=0.015)$ was significantly higher in the obese group compared to the normal weight infertile. The results also showed that the mean of T/E2 ratio was significantly lower in the infertile obese group vs overweight $(P=0.001)$ and normal weight infertile male ( $P=0.001)$ groups (Table 3$)$.

The correlation between WC and semen parameters and sex hormones was also assessed (Tables 4-5). WC cut-off was $102 \mathrm{~cm}$ and 74 (62\%) patients had $\mathrm{WC}<102 \mathrm{~cm}$ and 45 (38\%) patients had $\mathrm{WC}>102 \mathrm{~cm}$. Sperm count $(P<0.001)$, motile sperm $(P<0.001)$ and progressive sperm $(P<0.001)$ were significantly lower and the fraction of sperm with abnormal morphology $(P=0.009)$ was significantly higher in infertile males with $\mathrm{WC}>102 \mathrm{~cm}$ compared infertile males with $\mathrm{WC}<102 \mathrm{~cm}$ (Table 4).

In addition serum levels of LH $(P<0.001)$, FSH $(P<0.001)$, leptin $(P<0.001)$ and estradiol $(P=0.029)$ were significantly higher and serum levels of $\mathrm{T}(P=0.003)$ and $\mathrm{T} / \mathrm{E} 2(P=0.002)$ ratio were significantly lower in infertile males with $\mathrm{WC}>102 \mathrm{~cm}$ compared to infertile males with $\mathrm{WC}<102 \mathrm{~cm}$ (Table 5).

\section{Discussion}

People with a BMI of $\geq 30 \mathrm{~kg} / \mathrm{m}^{2}$ are considered as obese. However, body fat distribution, specifically in the 
Table I Characteristics of the Study Population According to the Different BMI Groups $(n=1$ I9)

\begin{tabular}{|c|c|c|c|c|}
\hline \multirow[t]{2}{*}{ Variables } & \multicolumn{3}{|l|}{ BMI } & \multirow[t]{2}{*}{$P$-value } \\
\hline & $\begin{array}{l}\text { Normal }(18.5-24.9 \mathrm{~kg} / \\
\left.\mathrm{m}^{2}\right)(\mathrm{n}=30)\end{array}$ & $\begin{array}{l}\text { Overweight }(25-29.9 \mathrm{~kg} / \\
\left.\mathrm{m}^{2}\right)(\mathrm{n}=56)\end{array}$ & $\begin{array}{l}\text { Obese }\left(\geq 30 \mathrm{~kg} / \mathrm{m}^{2}\right) \\
(\mathrm{n}=33)\end{array}$ & \\
\hline Age (year, mean $\pm S D$ ) & $33.66 \pm 4.7$ & $35.8 \pm 6.38$ & $33.57 \pm 5.73$ & $0.129^{\mathrm{a}}$ \\
\hline BMI $\left(\mathrm{kg} / \mathrm{m}^{2}\right)$ & $22.46 \pm 1.76^{d}$ & $27.49 \pm 1.31^{\mathrm{e}}$ & $34.33 \pm 3.25^{f}$ & $<0.001^{b}$ \\
\hline$W C(\mathrm{~cm})$ & $84.90 \pm 4.74^{d}$ & $96.96 \pm 5.65^{\mathrm{e}}$ & $111.48 \pm 9.52^{f}$ & $<0.001^{b}$ \\
\hline Education level, n (\%) & & & & $0.389^{c}$ \\
\hline Illiterate & 0 & I (2) & I (3) & \\
\hline High school & $7(23)$ & $18(32)$ & $9(27)$ & \\
\hline Diploma & $9(30)$ & $15(26)$ & $8(24)$ & \\
\hline College & $14(46)$ & $22(39)$ & $15(45)$ & \\
\hline Race, n (\%) & & & & $0.867^{c}$ \\
\hline Fars & $6(20)$ & $15(26)$ & $6(18)$ & \\
\hline Arab & $12(40)$ & $22(73)$ & $13(39)$ & \\
\hline Lor & II (36) & $16(28)$ & II (33) & \\
\hline Tork & I (3) & $2(3)$ & $2(6)$ & \\
\hline Kord & 0 & I (2) & 0 & \\
\hline Others & 0 & 0 & I (3) & \\
\hline Smoking, n (\%) & & & & $0.460^{c}$ \\
\hline Yes & $20(66)$ & $41(73)$ & $20(60)$ & \\
\hline No & $10(33)$ & $15(26)$ & $13(39)$ & \\
\hline Mobile, n (\%) & & & & $0.390^{c}$ \\
\hline Yes & $25(83)$ & $5 I(9 I)$ & $27(8 \mathrm{I})$ & \\
\hline No & $5(16)$ & $5(8)$ & $6(18)$ & \\
\hline Economic Situation, n (\%) & & & & $0.422^{c}$ \\
\hline Poor & $5(16)$ & $8(14)$ & $4(12)$ & \\
\hline Moderate & $23(76)$ & $36(64)$ & $21(63)$ & \\
\hline Good & $2(6)$ & $12(2 \mid)$ & $8(24)$ & \\
\hline Physical Activity, n (\%) & & & & $0.665^{c}$ \\
\hline Low & $16(54)$ & $28(50)$ & $14(43)$ & \\
\hline Moderate & $14(46)$ & $28(50)$ & $19(57)$ & \\
\hline High & 0 & 0 & 0 & \\
\hline Duration of Abstinence (day, mean \pm SD) & $3.01 \pm 0.66$ & $3.08 \pm 0.72$ & $3.06 \pm 0.49$ & $0.968^{\mathrm{a}}$ \\
\hline Infertility duration (years, mean $\pm S D$ ) & $2.66 \pm 1.62$ & $2.50 \pm 1.57$ & $2.98 \pm 1.67$ & $0.409^{\mathrm{a}}$ \\
\hline
\end{tabular}

Notes: Data are presented as mean \pm standard deviation $(\mathrm{SD})$ or frequency and percentage. Differences between the three BMI groups were tested using one-way analysis of variance (ANOVA), ${ }^{a}$ Welch and Brown-Forsythe; ${ }^{b}$ Chi-Square test; ${ }^{c}$ Post Hoc Tests: Dunnett T3; ${ }^{d-f}(P<0.00 I)$. P $<0.05$ was considered statistically significant.

Abbreviations: BMI, body mass index; WC, waist circumference.

abdominal region, is also considered as a marker that shows obesity. However, waist circumference is currently suggested as a more accurate marker of obesity. ${ }^{21}$ It was shown that obese men are three times more likely to have oligospermia, a sperm count of fewer than 15 million $/ \mathrm{mL}$, compared to healthy men with normal weight. ${ }^{22}$ As the reduction in fertility is accompanied with the increasing rates of obesity, it seems that obesity may be associated with male infertility. ${ }^{23}$
In the present study, the authors investigated the correlation among BMI, WC, and semen-analysis parameters as well as serum concentrations of sex hormones. We observed that adiposity is related to some sperm parameters and serum concentration of some sex hormones when assessed by BMI as well as WC. Correspondingly, this was generally consistent with some previous studies that reported the negative association among obesity and total sperm counts or concentration, $^{7,24,25}$ sperm motility, ${ }^{6,7,24-26}$ and normal 
Table 2 Sperm Analysis Results in the Different BMI Groups $(n=119)$

\begin{tabular}{|c|c|c|c|c|}
\hline \multirow[t]{2}{*}{ Variables } & \multicolumn{3}{|l|}{ BMI } & \multirow[t]{2}{*}{$P$-value } \\
\hline & $\begin{array}{l}\text { Normal }\left(18.5-24.9 \mathrm{~kg} / \mathrm{m}^{2}\right) \\
(n=30)\end{array}$ & $\begin{array}{l}\text { Overweight }\left(25-29.9 \mathrm{~kg} / \mathrm{m}^{2}\right) \\
(n=56)\end{array}$ & $\begin{array}{l}\text { Obese }\left(\geq 30 \mathrm{~kg} / \mathrm{m}^{2}\right) \\
(n=33)\end{array}$ & \\
\hline Volume $(\mathrm{mL})$ & $2.48 \pm 1.41$ & $3.54 \pm 1.93$ & $3.26 \pm 1.27$ & $0.54^{\mathrm{b}}$ \\
\hline Sperm count $(\mathrm{M} / \mathrm{mL})$ & $25.63 \pm 10.72^{f}$ & $16.07 \pm 10.33^{g}$ & $12.57 \pm 9.70^{\mathrm{h}}$ & $<0.001^{b}$ \\
\hline Motile sperm (\%) & $38.06 \pm 8.70^{c}$ & $34.14 \pm 10.24^{d}$ & $27.72 \pm 9.28^{\mathrm{e}}$ & $<0.001^{\mathrm{a}}$ \\
\hline Progressive sperm (\%) & $30.26 \pm 7.87^{i}$ & $25.98 \pm 8.78^{\mathrm{j}}$ & $18.89 \pm 8.46^{k}$ & $<0.00 I^{a}$ \\
\hline Normal sperm morphology (\%) & $1.36 \pm 1.37$ & $1.28 \pm 1.26$ & $0.96 \pm 0.98$ & $0.544^{\mathrm{b}}$ \\
\hline
\end{tabular}

Notes: Data are presented as mean \pm standard deviation (SD). Differences between the three BMI groups were tested using one-way analysis of variance ${ }^{a}(A N O V A)$. ${ }^{\mathrm{b}}$ Kruskal-Wallis test. Post Hoc Tests for normal distribution data. (a) LSD; ${ }^{\mathrm{c}, \mathrm{d}}(P=0.074) ;{ }^{\mathrm{e}}(P<0.00 \mathrm{I}) ;{ }^{\mathrm{d}, \mathrm{e}}(P=0.003) ;{ }^{\mathrm{ij}}(P=0.027) ;{ }^{\mathrm{k}}(P<0.00 \mathrm{l}) ;{ }^{\mathrm{j}, \mathrm{k}}(P<0.00 \mathrm{I})$. Pairwise comparison for non-normal distribution data (b) were tested using Mann-Whitney test ${ }^{\mathrm{f} g}(P<0.00 \mathrm{I}),{ }^{\mathrm{h}}(P<0.00 \mathrm{I}),{ }^{\mathrm{g}}, \mathrm{h}(P=0.038) . P<0.05$ was considered statistically significant.

Abbreviations: $\mathrm{M} / \mathrm{mL}$, million per milliliter; $\mathrm{BMI}$, body mass index.

Table 3 Hormones Analysis Results in the Different BMI Groups $(n=119)$

\begin{tabular}{|c|c|c|c|c|}
\hline \multirow{2}{*}{ Variables } & \multicolumn{3}{|l|}{ BMI } & \multirow{2}{*}{$P$-value } \\
\hline & Normal $\left(18.5-24.9 \mathrm{~kg} / \mathrm{m}^{2}\right)(\mathrm{n}=30)$ & Overweight $\left(25-29.9 \mathrm{~kg} / \mathrm{m}^{2}\right)(\mathrm{n}=56)$ & Obese $\left(\geq 30 \mathrm{~kg} / \mathrm{m}^{2}\right)(\mathrm{n}=33)$ & \\
\hline LH & $3.61 \pm 1.32^{c}$ & $7.93 \pm 1.94^{\mathrm{d}}$ & $12.17 \pm 2.28^{\mathrm{e}}$ & $<0.00 I^{\mathrm{a}}$ \\
\hline $\mathrm{FSH}$ & $2.83 \pm 0.95^{c}$ & $6.81 \pm 2.32^{\mathrm{d}}$ & $9.27 \pm 2.66^{\mathrm{e}}$ & $<0.001^{\mathrm{b}}$ \\
\hline SHBG & $12.94 \pm 7.70$ & $|2.20 \pm 6.6|$ & $|1.30 \pm 5.5|$ & $0.619^{\mathrm{a}}$ \\
\hline PRL & $313.79 \pm 177.15$ & $329.25 \pm 195.82$ & $385.81 \pm 271.40$ & $0.357^{\mathrm{a}}$ \\
\hline Leptin & $18.20 \pm 8.21^{\mathrm{c}}$ & $25.32 \pm 5.98^{d}$ & $33.93 \pm 7.47^{\mathrm{e}}$ & $<0.001^{\mathrm{a}}$ \\
\hline Estradiol & $22.77 \pm 10.65^{f}$ & $25.55 \pm 13.02$ & $31.03 \pm 15.59^{g}$ & $0.042^{\mathrm{a}}$ \\
\hline $\mathrm{T}$ & $4.32 \pm 2.27$ & $4.27 \pm 2.43^{f}$ & $3.13 \pm 1.24^{g}$ & $0.033^{\mathrm{b}}$ \\
\hline T/E2 ratio & $0.22 \pm 0.14^{\mathrm{h}}$ & $0.19 \pm 0.13^{\mathrm{i}}$ & $0.11 \pm 0.06^{\mathrm{j}}$ & $0.002^{\mathrm{b}}$ \\
\hline
\end{tabular}

Notes: Data are presented as mean \pm standard deviation (SD). Differences between the three BMl groups were tested using one-way analysis of variance (ANOVA), ${ }^{b}$ Way Kruskal-Wallis test. Post Hoc Tests for normal distribution data a LSD; ${ }^{c-e}(P<0.001) ;{ }^{g}$ vs ${ }^{f}(P=0.015)$ Pairwise comparison for non-normal distribution data (b) were tested using Mann-Whitney test $\left({ }^{c-e}(P<0.00 I),{ }^{g}\right.$ vs ${ }^{f}(P=0.043),{ }^{i}$ vs $[h(P=0.001): i(P=0.001)]$.

Abbreviations: BMI, body mass index; LH, luteinizing hormone; FSH, follicle-stimulating hormone; SHBG, sex hormone-binding globulin; PRL, prolactin; T, testosterone; E2, estradiol.

Table 4 Sperm Analysis Results in the Different WC Groups $(n=119)$

\begin{tabular}{|l|l|l|l|}
\hline \multirow{2}{*}{ Variables } & \multicolumn{3}{|l|}{ WC } \\
\cline { 2 - 4 } & $\begin{array}{l}\text { WC }<\text { 102 cm } \\
(\mathbf{n = 7 4 )}\end{array}$ & $\begin{array}{l}\text { WC } \geq \mathbf{I 0 2} \mathbf{~ c m} \\
(\mathbf{n = 4 5 )}\end{array}$ & P-alue \\
\hline Volume (mL) & $3.21 \pm 1.75$ & $3.16 \pm 2.26$ & $0.34 I^{\mathrm{b}}$ \\
Sperm count (M/mL) & $20.52 \pm 10.55$ & $12.55 \pm 10.88$ & $<0.00 I^{\mathrm{b}}$ \\
Motile sperm (\%) & $36.48 \pm 8.93$ & $28.20 \pm 10.35$ & $<0.00 I^{\mathrm{b}}$ \\
Progressive sperm (\%) & $\begin{array}{l}28.28 \pm 8.13 \\
19.85 \pm 9.09\end{array}$ & $<0.00 I^{\mathrm{a}}$ \\
Normal sperm & $1.45 \pm 1.32$ & $0.82 \pm 0.91$ & $0.009^{\mathrm{b}}$ \\
morphology (\%) & & & \\
\hline
\end{tabular}

Notes: Data are presented as mean \pm standard deviation (SD). ${ }^{a}$ Differences between the three WC groups were tested using independent sample $t$-test; bMann-Whitney test. $P<0.05$ was considered statistically significant.

Abbreviations: $\mathrm{M} / \mathrm{mL}$, million per milliliter; WC, waist circumference.

sperm morphology. ${ }^{7,24,27,28}$ Although there is some existing support for the idea suggesting the effects of obesity on reproductive potential, several studies have indicated no connection between BMI and sperm parameters. However, over half of the studies included self-reported measures of BMI. Moreover, adiposity had been only assessed by BMI. Notably, distribution of body fat, as assessed by WC, may provide a more robust measure of the adverse metabolic implications of excess body size rather than BMI. ${ }^{29}$ There are a few studies that have investigated the effects of WC on semen profile. A negative correlation between sperm counts and WC was observed in infertile men in Fejes et al and Hammiche et al studies. ${ }^{18,30}$ In the present study, the sperm parameter quality was higher in infertile males with normal WC compared to overweight and obese infertile males. However, it is still unclear whether a similar relationship exists in men who are not infertile.

Therefore, the hypotheses on the link between obesity and male infertility are controversial yet. However, by considering the undesirable effects of overweight and obesity on health, it is suggested to be cautious in this 
Table 5 Hormones Analysis Results in the Different WC Groups $(n=119)$

\begin{tabular}{|l|l|l|l|}
\hline \multirow{2}{*}{ Variables } & \multicolumn{3}{|l|}{ WC } \\
\cline { 2 - 4 } & $\begin{array}{l}\text { WC<102 cm } \\
(\mathbf{n}=\mathbf{7 4})\end{array}$ & $\begin{array}{l}\text { WC } \mathbf{1 0 2} \mathbf{~ c m ~ ( n = ~} \\
\text { 45) }\end{array}$ & P-value \\
\hline LH & $6.07 \pm 2.60$ & $11.22 \pm 2.79$ & $<0.00 I^{\mathrm{a}}$ \\
FSH & $5.18 \pm 2.77$ & $8.64 \pm 2.69$ & $<0.00 I^{\mathrm{a}}$ \\
SHBG & $12.77 \pm 7.00$ & $11.09 \pm 5.80$ & $0.252^{\mathrm{b}}$ \\
PRL & $330.97 \pm 184.39$ & $357.59 \pm 259.83$ & $0.898^{\mathrm{b}}$ \\
Leptin & $22.25 \pm 8.18$ & $31.93 \pm 6.93$ & $<0.00 I^{\mathrm{b}}$ \\
Estradiol & $25.05 \pm 13.90$ & $28.54 \pm 12.69$ & $0.029^{\mathrm{b}}$ \\
T & $4.47 \pm 2.43$ & $3.15 \pm 1.30$ & $0.003^{\mathrm{b}}$ \\
T/E2 ratio & $0.21 \pm 0.14$ & $0.12 \pm 0.07$ & $0.002^{\mathrm{b}}$ \\
\hline
\end{tabular}

Notes: Data are presented as mean \pm standard deviation (SD). ${ }^{a}$ Differences between the three WC groups were tested using independent sample $t$-test, bMann-Whitney test. $P<0.05$ was considered statistically significant.

Abbreviations: WC, waist circumference; LH, luteinizing hormone; FSH, folliclestimulating hormone; SHBG, sex hormone-binding globulin; PRL, prolactin; T, testosterone; E2, estradiol.

regard and more emphasis should be placed on the importance of having a normal weight.

Obesity may affect male fertility directly or indirectly through several possible mechanisms, by alterations in hormonal profiles. In human beings, increase in BMI reduces plasma sex hormone-binding globulin (SHBG) that results in lower testosterone and higher estrogen levels. ${ }^{4,11,31-36}$ Additionally, the state of obesity itself perpetuates high estrogen levels, due to a greater white adipose tissue. ${ }^{37}$ Correspondingly, these hormonal changes were also observed in the present study. Aromatase cytochrome P450, which is responsible for the key step in biosynthesis of estrogens, is highly expressed in white adipose tissue. Due to a high availability of aromatase enzyme, there is an increased conversion of androgens into estrogens. In addition, it was previously stated that these high estrogen levels have a deleterious effect on spermatogenesis by controlling the levels of testosterone levels through a negative feedback mechanism on the hypothalamus. ${ }^{21,22}$ It was found that obesity also increases scrotal temperatures due to the increased scrotal adiposity, which may damage spermatogenesis and impair semen parameters (decreased total sperm count, concentration, and motility; and increased DNA fragmentation index). However, in a recent meta-analysis, it has been concluded that there is insufficient data to demonstrate a positive association between BMI and sperm DNA fragmentation., It has also been suggested that obesity may directly alter spermatogenesis and Sertoli cell function, as indicated by the more severe decrease of inhibition of B levels compared with the decrease of $\mathrm{FSH}^{38}$ Moreover, it was suggested that obesity may directly stimulate semen abnormalities through the increased production of $\mathrm{ROS}^{8,39}$ and inflammatory mediators impairing testicular and epididymal tissues. The elevated levels of inflammatory mediators including TNF- $\alpha$ and IL-6 as well as the decreased levels of vascular endothelial growth factor (VEGF) were observed in the seminal plasma of obese males, which may affect the quality of semen. ${ }^{40}$ Therefore, it is suggested that obesity may alter the systematic and local environment necessary for spermatogenesis in testis and sperm maturation in epididymis, which may finally result in poor sperm quality including decreased sperm motility, abnormal morphology of sperm, acrosome reaction, the altered membrane lipids, and increased damage to DNA. Furthermore, some recent studies indicated that the epigenetic changes including methylation of sperm DNA and modification of non-coding RNA may be consequences of the increased adiposity, which are associated with changes in BMI and reproduction. ${ }^{41}$ Additionally, the state of obesity itself causes high plasma leptin levels. Accordingly, synthesis of leptin, as the key regulatory adipokine, generally occurs in the white adipose tissue and is generally found in high levels in serum of obese men. ${ }^{7}$ Despite the essentiality of leptin for a normal reproductive function, in excessive levels, it can have detrimental effects on the male reproductive system. The collective observations from human and animal studies have pointed out leptin as a link between infertility and obesity, a suggestion that is corroborated by findings of low sperm count, the increased sperm abnormalities, oxidative stress, and the increased leptin levels in obese men. ${ }^{42,43}$ Moreover, leptin may act via its receptors on the KISS1 neurons, which stimulate GnRH release from the hypothalamus. In this regard, KISS1 neurons project to both GnRH neurons and the NPY neurons. Thus, leptin can prevent the GnRH inhibition by the NPY neurons, acting through KISS1. It is hypothesized that obese men may develop leptin resistance, which may consequently lead to the suppression of KISS1 neuron activities as well as the increased NPY levels, causing an inhibition of GnRH neurons. This eventually affects the release of gonadotropins from the pituitary, reduces steroidogenesis, and results in hypogonadotropic hypogonadism. ${ }^{11}$ In addition, daily leptin administration to normal-weight rats has been shown to result in similar abnormalities in sperm parameters. Although the major pathways causing these abnormalities still remain unidentified, these adverse effects have been attributed to the leptin-induced increased oxidative stress and uncontrolled production of reactive oxygen species 
(ROS). ${ }^{44,45}$ At physiological levels, ROS play significant roles in sperm maturation, capacitation, and acrosome reaction. Moreover, at pathological levels, ROS impair testicular germ cell proliferation, which negatively affects sperm plasma membrane fluidity, impairs sperm motility, and increases sperm DNA damage. ${ }^{43}$ It seems that weight loss may be an effective treatment approach for obesity linked with male infertility; however, few controlled trials have been conducted to investigate its significant effects. Though there is a general agreement in these studies. It was found that men who lost their body weight following a healthy diet and exercise, had increased levels of androgen, inhibition of B, improved semen parameters, ${ }^{31,46,47}$ increased sexual hormone binding globulin (SHBG), and decreased serum concentrations of insulin and leptin. In addition, a restriction in caloric intake and the increased exercise were found to be effective factors in improving erectile function, particularly in men with obesity and diabetes mellitus. ${ }^{48}$ Moreover, a preliminary prospective double-armed study recently found that a massive weight loss obtained with bariatric surgery was also associated with improvements in some parameters of the semen. ${ }^{49}$

This study had some limitations including small sample size, lack of a normal weight fertile control group, and existence of smokers in the study. Further studies with a high methodological quality and adequate sample sizes are required to improve our knowledge regarding the relationship between obesity and infertility.

\section{Conclusions}

We concluded that overweight and obesity in infertile men compared to infertile men with normal weight may worsen the infertility situation. So, considering the relationship between the increasing prevalence rate of obesity and the decreased male fertility, it is suggested that clinicians should have further awareness on the relationship among obesity, infertility, and underlying mechanisms to provide an effective treatment.

\section{Abbreviations}

BMI, body mass index; DNA, deoxyribonucleic acid; E2, estradiol; FSH, follicle-stimulating hormone; GnRH, gonadotropin releasing hormone; IL-6, interleukin 6; LH, luteinizing hormone; NPY, neuropeptide Y; ANOVA, oneway analysis of variance; PRL, prolactin; RNA, ribonucleic acid; ROS, reactive oxygen species; SHBG, sex hormone-binding globulin; SD, standard deviation; T, testosterone; TNF $\alpha$, tumor necrosis factor alpha; VEGF, vascular endothelial growth factor; WC, waist circumference; WHO, World Health Organization.

\section{Acknowledgments}

This research was supported by Vice Chancellor of Ahvaz Jundishapur University of Medical Sciences, Ahvaz, Iran. The authors thank Vice Chancellor of Ahvaz Jundishapur University of Medical Sciences for their supports and all the patients for their participation in this study.

\section{Author Contributions}

All authors contributed to data analysis, drafting or revising the article, have agreed on the journal to which the article will be submitted, gave final approval of the version to be published, and agree to be accountable for all aspects of the work.

\section{Disclosure}

The authors report no conflicts of interest in this work.

\section{References}

1. Moussa HN, Alrais MA, Leon MG, Abbas EL, Sibai BM. Obesity epidemic: impact from preconception to postpartum. Future Sci OA. 2016;2(3):FSO137. doi:10.4155/fsoa-2016-0035

2. Bieniek JM, Kashanian JA, Deibert CM, et al. Influence of increasing body mass index on semen and reproductive hormonal parameters in a multi-institutional cohort of subfertile men. Fertil Steril. 2016;106 (5):1070-1075. doi:10.1016/j.fertnstert.2016.06.041

3. Dubeux VT, Renovato T, Esteves AC, André L, de Oliveira A, Penna IA. The impact of obesity on male fecundity: a Brazilian study. JBRA Assisted Reprod. 2016;20(3):137. doi:10.5935/1518-055 7.20160031

4. Aggerholm AS, Thulstrup AM, Toft G, Ramlau-Hansen $\mathrm{CH}$, Bonde JP. Is overweight a risk factor for reduced semen quality and altered serum sex hormone profile? Fertil Steril. 2008;90 (3):619-626. doi:10.1016/j.fertnstert.2007.07.1292

5. Sermondade N, Faure C, Fezeu L, et al. BMI in relation to sperm count: an updated systematic review and collaborative meta-analysis. Hum Reprod Update. 2012;19(3):221-231. doi:10.1093/humupd/ dms050

6. Raad G, Azouri J, Rizk K, et al. Adverse effects of paternal obesity on the motile spermatozoa quality. PLoS One. 2019;14(2):e0211837. doi:10.1371/journal.pone.0211837

7. Ramaraju GA, Teppala S, Prathigudupu K, et al. Association between obesity and sperm quality. Andrologia. 2018;50:3. doi:10.1111/ and. 12888

8. Han RY, Ma J, Ma J, et al. [Correlation of reproductive hormone levels and seminal plasma oxidative stress with semen quality in obese males]. Zhonghua Nan Ke Xue = National Journal of Andrology. 2018;24(5):419-424. Chinese.

9. Guo D, Wu W, Tang Q, et al. The impact of BMI on sperm parameters and the metabolite changes of seminal plasma concomitantly. Oncotarget. 2017;8(30):48619-48634. doi:10.18632/oncotarget.14 950

10. Vermeulen A. Environment, human reproduction, menopause, and andropause. Environ Health Perspect. 1993;101(suppl 2):91-100. doi:10.1289/ehp.93101s291

11. Leisegang K, Sengupta P, Agarwal A, Henkel R. Obesity and male infertility: mechanisms and management. Andrologia. 2020;e13617. 
12. MacDonald A, Herbison G, Showell M, Farquhar C. The impact of body mass index on semen parameters and reproductive hormones in human males: a systematic review with meta-analysis. Hum Reprod Update. 2009;16(3):293-311.

13. Hammoud AO, Gibson M, Peterson CM, Meikle AW, Carrell DT. Impact of male obesity on infertility: a critical review of the current literature. Fertil Steril. 2008;90(4):897-904. doi:10.1016/j.fertnstert. 2008.08.026

14. Macdonald AA, Stewart AW, Farquhar CM. Body mass index in relation to semen quality and reproductive hormones in New Zealand men: a cross-sectional study in fertility clinics. Human Reprod. 2013;28(12):3178-3187. doi:10.1093/humrep/det379

15. Rufus O, James O, Michael A. Male obesity and semen quality: any association? Int J Reprod Biomed. 2018;16(4):285-290.

16. Eskandar M, Al-Asmari M, Babu Chaduvula S, et al. Impact of male obesity on semen quality and serum sex hormones. Adv Urol. 2012;2012.

17. Relwani R, Berger D, Santoro N, et al. Semen parameters are unrelated to BMI but vary with SSRI use and prior urological surgery. Reprod Sci. 2011;18(4):391-397. doi:10.1177/193371911 0385708

18. Fejes I, Koloszar S, Szollosi J, Zavaczki Z, Pal A. Is semen quality affected by male body fat distribution? Andrologia. 2005;37 (5):155-159. doi:10.1111/j.1439-0272.2005.00671.x

19. Catanzariti F, Cantoro U, Lacetera V, Muzzonigro G, Polito M. Comparison between WHO (World Health Organization) 2010 and WHO 1999 parameters for semen analysis-interpretation of 529 consecutive samples. Archivio Italiano di Urologia e Andrologia. 2013;85(3):125-129. doi:10.4081/aiua.2013.3.125

20. Moore S, Hall JN, Harper S, Lynch JW. Global and national socioeconomic disparities in obesity, overweight, and underweight status. J Obes. 2010;2010.

21. Du Plessis SS, Cabler S, McAlister DA, Sabanegh E, Agarwal A. The effect of obesity on sperm disorders and male infertility. Nat Rev Urol. 2010;7(3):153-161. doi:10.1038/nrurol.2010.6

22. Hammoud AO, Gibson M, Peterson CM, Hamilton BD, Carrell DT. Obesity and male reproductive potential. $J$ Androl. 2006;27 (5):619-626. doi:10.2164/jandrol.106.000125

23. Swan SH, Elkin EP, Fenster L. The question of declining sperm density revisited: an analysis of 101 studies published 1934-1996. Environ Health Perspect. 2000;108(10):961-966. doi:10.1289/ehp.00108961

24. Hammoud AO, Wilde N, Gibson M, Parks A, Carrell DT, Meikle AW. Male obesity and alteration in sperm parameters. Fertil Steril. 2008;90(6):2222-2225. doi:10.1016/j.fertnstert.2007.10.011

25. Ma J, Wu L, Zhou Y, et al. Association between BMI and semen quality: an observational study of 3966 sperm donors. Hum Reprod. 2019;34(1):155-162. doi:10.1093/humrep/dey328

26. Magnusdottir EV, Thorsteinsson T, Thorsteinsdottir S, Heimisdottir M, Olafsdottir K. Persistent organochlorines, sedentary occupation, obesity and human male subfertility. Human Reprod. 2005;20(1):208-215. doi:10.1093/humrep/deh569

27. Stewart TM, Liu DY, Garrett C, Jorgensen N, Brown EH, Baker HW. Associations between andrological measures, hormones and semen quality in fertile Australian men: inverse relationship between obesity and sperm output. Human Reprod. 2009;24(7):1561-1568. doi:10.1093/ humrep/dep075

28. Andersen JM, Herning H, Aschim EL, et al. Body mass index is associated with impaired semen characteristics and reduced levels of anti-mullerian hormone across a wide weight range. PLoS One. 2015;10(6):e0130210. doi:10.1371/journal.pone.0130210

29. Janssen I, Katzmarzyk PT, Ross R. Waist circumference and not body mass index explains obesity-related health risk. Am J Clin Nutr. 2004;79(3):379-384. doi:10.1093/ajcn/79.3.379
30. Hammiche F, Laven JS, Twigt JM, Boellaard WP, Steegers EA, Steegers-Theunissen RP. Body mass index and central adiposity are associated with sperm quality in men of subfertile couples. Human Reprod. 2012;27(8):2365-2372. doi:10.1093/humrep/des177

31. Chavarro JE, Toth TL, Wright DL, Meeker JD, Hauser R. Body mass index in relation to semen quality, sperm DNA integrity, and serum reproductive hormone levels among men attending an infertility clinic. Fertil Steril. 2010;93(7):2222-2231. doi:10.1016/j. fertnstert.2009.01.100

32. Fejes I, Koloszár S, Závaczki Z, Daru J, Szöllösi J, Pál A. Effect of body weight on testosterone/estradiol ratio in oligozoospermic patients. Arch Androl. 2006;52(2):97-102. doi:10.1080/01485010500 315479

33. Hinz S, Rais-Bahrami S, Kempkensteffen C, Weiske WH, Miller K, Magheli A. Effect of obesity on sex hormone levels, antisperm antibodies, and fertility after vasectomy reversal. Urology. 2010;76 (4):851-856. doi:10.1016/j.urology.2010.01.055

34. Hofny ER, Ali ME, Abdel-Hafez HZ, et al. Semen parameters and hormonal profile in obese fertile and infertile males. Fertil Steril. 2010;94(2):581-584. doi:10.1016/j.fertnstert.2009.03.085

35. Pauli EM, Legro RS, Demers LM, Kunselman AR, Dodson WC, Lee PA. Diminished paternity and gonadal function with increasing obesity in men. Fertil Steril. 2008;90(2):346-351. doi:10.1016/j.fertnstert.2007.06.046

36. Tunc O, Bakos HW, Tremellen K. Impact of body mass index on seminal oxidative stress. Andrologia. 2011;43(2):121-128. doi:10.1111/j.1439-0272.2009.01032.x

37. Wake DJ, Strand M, Rask E, et al. Intra-adipose sex steroid metabolism and body fat distribution in idiopathic human obesity. Clin Endocrinol (Oxf). 2007;66(3):440-446. doi:10.1111/j.1365-2265.2007.02755.x

38. Winters SJ, Wang C, Abdelrahaman E, Hadeed V, Dyky MA, Brufsky A. Inhibin-B levels in healthy young adult men and prepubertal boys: is obesity the cause for the contemporary decline in sperm count because of fewer Sertoli cells? J Androl. 2006;27 (4):560-564. doi:10.2164/jandrol.05193

39. Adewoyin M, Ibrahim M, Roszaman R, et al. Male infertility: the effect of natural antioxidants and phytocompounds on seminal oxidative stress. Diseases (Basel, Switzerland). 2017;5:1.

40. Han RY, Ma J, Ma JY, et al. [Correlation of semen parameters with inflammatory factors in the seminal plasma of obese males]. Zhonghua Nan Ke Xue = National Journal of Andrology. 2017;23 (10):894-898. Chinese.

41. Liu Y, Ding Z. Obesity, a serious etiologic factor for male subfertility in modern society. Reproduction (Cambridge, England). 2017;154 (4):R123-r131. doi:10.1530/REP-17-0161

42. Almabhouh F, Abdul Aziz NAA, Durairajanayagam D, Singh HJ. Could leptin be responsible for the reproductive dysfunction in obese men? Reprod Biol. 2020;20(1):106-110. doi:10.1016/j. repbio.2020.01.003

43. Malik IA, Durairajanayagam D, Singh HJ. Leptin and its actions on reproduction in males. Asian J Androl. 2019;21(3):296-299. doi:10.4103/aja.aja_98_18

44. Haron MN, D'Souza UJA, Jaafar H, Zakaria R, Singh HJ. Exogenous leptin administration decreases sperm count and increases the fraction of abnormal sperm in adult rats. Fertil Steril. 2010;93(1):322-324. doi:10.1016/j.fertnstert.2009.07.995

45. Abbasihormozi S, Shahverdi A, Kouhkan A, Cheraghi J, Akhlaghi AA, Kheimeh A. Relationship of leptin administration with production of reactive oxygen species, sperm DNA fragmentation, sperm parameters and hormone profile in the adult rat. Arch Gynecol Obstet. 2013;287 (6):1241-1249. doi:10.1007/s00404-012-2675-x

46. Kasturi SS, Tannir J, Brannigan RE. The metabolic syndrome and male infertility. J Androl. 2008;29(3):251-259. doi:10.2164/jandrol. 107.003731 
47. Hakonsen LB, Thulstrup AM, Aggerholm AS, et al. Does weight loss improve semen quality and reproductive hormones? Results from a cohort of severely obese men. Reprod Health. 2011;8:24. doi:10.1186/17424755-8-24

48. Hannan JL, Maio MT, Komolova M, Adams MA. Beneficial impact of exercise and obesity interventions on erectile function and its risk factors. $J \quad$ Sex Med. 2009;6(Suppl 3):254-261. doi:10.1111/j.17436109.2008.01143.x
49. Samavat J, Cantini G, Lotti F, et al. Massive weight loss obtained by bariatric surgery affects semen quality in morbid male obesity: a preliminary prospective double-armed study. Obes Surg. 2018;28(1):69-76. doi:10.1007/s11695-017-2802-7

\section{Publish your work in this journal}

Research and Reports in Urology is an international, peer-reviewed, open access journal publishing original research, reports, editorials, reviews and commentaries on all aspects of adult and pediatric urology in the clinic and laboratory including the following topics: Pathology, pathophysiology of urological disease; Investigation and treatment of urological disease; Pharmacology of drugs used for the treatment of urological disease. The manuscript management system is completely online and includes a very quick and fair peer-review system, which is all easy to use. Visit http://www.dovepress.com/ testimonials.php to read real quotes from published authors. 